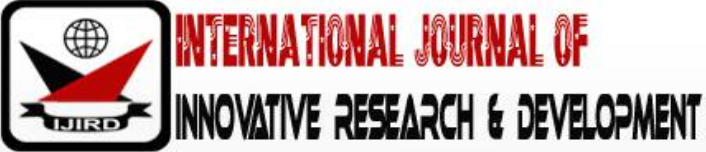

ISSN 2278 - 0211 (Online)

\section{Analysis of Composite Propellants Formulated from Maize Stalk and Pawpaw Stem}

OA Babatunde
Professor of Chemistry, Department of Chemistry,
Nigerian Defense Academy, Kaduna, Nigeria
D R Hassan
Retired Colonel, Nigerian Army, Nigeria
Dr. MM Namadi
Senior Lecturer, Department of Chemistry,
Nigerian Defense Academy, Kaduna, Nigeria

\section{Abstract:}

Plant biomass (Carbon) was sourced from maize stalk and paw paw stem were used as fuel o composite solid propellant. Composite solid propellant was conducted using three ratios in this order; Ammonium nitrate, Biomass (Carbon), Sulphur, Starch and Gum Arabic as binders in ratios of 80:16:2:2 (Cohen), 65:20:12:3 (Tenny) and 85:10:4:1 (proposed ratio) by mechanical means of using mortar and pestle. The formulated composite propellants were characterized using Differential Scanning colorimeter (DSC), Scanning Electron Microscope (SEM) and Fourier Transform Infrared (FTIR). The FTIR and SEM results indicated some similarities of interaction with the individual components (the ammonium nitrate, biomass (Carbon), Sulphur, Starch and Gum Arabic (binders) displayed by the different peaks and functional groups indicating formation of composite solid propellant. From the DSC results, exothermic peaks range from $184-250^{\circ} \mathrm{C}$ while the endothermic peaks range from $40-168^{\circ} \mathrm{C}$. thereby indicating the burning rate ability of the propellants in space.

Keywords: Composite, formulation, propellant. etc

\section{Introduction}

Propellants are chemical as substances which burn at an extremely rapid rate producing large volumes of gases. Propellants are employed to initiate emergency seat ejection systems from aircrafts, used to accelerate a projectile in the bore of a gun and propel rockets and missiles along their flight paths, launch aircrafts into the air (Daintith, 2000). ). Propellants have existed for centuries in the form of black powder and later develop into smokeless (nitrocellulose) and then composite. These propellants exhibit different characteristics which challenge scientist to research and look into the behaviour of propellants, it is the quest for such that led to different research work on propellant characterization (Niklos, 2004).

Composite propellant, it contains mainly an oxidizer such as ammonium nitrate, ammonium perchlorate, chlorate mixed with fuel such as metal powder or carbon and also binders such as synthetic rubber, resins, polymeric binders. The composite propellant is more stable and easily kept for storage than the liquid propellant which is more cumbersome and difficult to control. It is mostly used for rocket purposes (Tenny, 1998The major ingredients of modern military propellants are actually few. They consist of fuels, oxidizers and binders (polymers), and are fairly basic in their chemical nature and structure. The minor ingredients, used to assist or tie together the major ingredients, are more numerous and sometimes more complex. The interactions of these major and minor ingredients, when combined into a practical solid propellant, are complex. These interactions can take place at all stages of manufacture, storage, and use. The ingredients themselves represent output of the conventional chemical and explosive industries (although a few, like Nitroglycerin, are produced locally); however, the combination of these ingredients into a propellant is still thought of by some as a 'black art.' Making it into a science is what has justified the expenditure of so many millions of dollars over the past 50 years (Kevin, 1986). A powdered oxidizer and powdered metal fuel are intimately mixed and immobilized with a rubbery binder (that also acts as a fuel). Composite propellants are often either Ammonium Nitrate-based (ANCP) or Ammonium Per chlorate-based (APCP). Ammonium Nitrate composite propellant often uses magnesium and/or Aluminium as fuel and delivers medium performance (Isp of about 210sec) whereas Ammonium Per chlorate Composite Propellant often uses aluminium fuel and delivers high performance (vacuum Isp up to 296sec with a single piece nozzle or 304sec with a high area ratio telescoping nozzle). Aluminium is used as fuel because it has a reasonable specific energy density, a high volumetric energy density, and is difficult to ignite accidentally. Composite propellants are cast, and retain their shape 
after the rubber binder, such as Hydroxyl- Terminated Polybutadiene (HTPB) Carboxyterminated Polybutadience (CTPB) and Polybutatadiene Acylonitrile (PBAN).

\section{Materials and Method}

\subsection{Sample Collection and Preparation}

The maize stalk was obtained from 3 farms located along Kaduna- Zaria Road, Airport Road and Kaduna- Abuja Road while paw- paw stem was collected from 3 farms along Airport Road Kaduna, Kaduna- Abuja Road and along Kaduna- Kujama Road.. The samples were collected in bags separately. The maize stalk and pawpaw stem were cut into smaller sizes, dried at room temperature and were labeled for charring labeled before charring. The gum Arabic was collected from acacia trees (acacia segalis) that produce the gummy sap using a knife which is located in Maigatari, Jigawa State while the starch flour was sourced from cassava tubers obtained from the open market. The collected cassava tubers were peeled and then washed to remove dirt. The washed cassava was then grinded into paste with a grinding machine and then kept in a bowl. The grinded cassava powder was sieved using a 20 micro size pores sieve into a clean bowl and allowed to settle for 3 hours, decanted and spread on a wide bowl to dry for 24 hours at room temperature. A fine dried powder was obtained and kept in a plastic container and labeled. The samples were coded as indicated in Table 1

\subsection{Charring of Samples}

The dried samples from, paw-paw stem and maize, stalks were charred to get the charcoal which constitutes mainly carbon (Biomass) out using an air tight Germany Muffle Furnace with Model Number SXL 1006 set at $400{ }^{\circ} \mathrm{C}$ for one hour. The prepared samples of the plants were weighed $(400 \mathrm{~g})$ each and inserted into the crucible having the size of the muffle furnace chamber for charring with a set temperature of $250^{\circ} \mathrm{C}$ for one hour. The obtained charcoal were then grinded to powdered form separately using mortar and pestle and labeled separately, kept under sealed containers.

\subsection{Formation of Propellants}

The formulation of the Composite propellants were done according to the ratios of Tenny (1998) (65:20:12:3), Cohen (1997)(80:16:2:2) and proposed (85:10:4:1) where exactly 32.5g ammonium nitrate, $10 \mathrm{~g}$ of carbon, $6 \mathrm{~g}$ of sulphur and $1.5 \mathrm{~g}$ of starch were weighed and transferred into mortar and mixed thoroughly. The weights of the components were measured and mixed in such a way to achieve the Tenny ratio of 65:20:12:3 in 1997

The same procedure was repeated with weights of components to achieve Cohen ratios of $(80: 16: 2: 2)$ and the proposed ratio of $(85: 10: 4: 1)$.

Exactly the same process was repeated for gum Arabic as binder.

\subsection{Characterization of the Propellants}

\subsubsection{Differential Scanning Calorimeter (DCS)}

DSC machine model DSC2 MERTNER TELEDO was used for thermal analysis of formulated composite propellants where $0.5 \mathrm{~g}$ of the propellants were measured into crucibles and introduced into the sample holder compartment of the machine and the chamber was closed. The samples were run between $30-500^{\circ} \mathrm{C}$ for the analysis to obtain the transition phase, endothermic and exothermic values

\subsubsection{Scanning Electron Microscope (SEM)}

Phenomenon PROX SEM machine with model number 4.5.3 was used to determined micro grain images of the formulated composite propellants. Samples were pulverized to particle size of about 0.15 micron $(100 \mathrm{mesh})$ separately using Jaw Crusher. Exactly $0.5 \mathrm{~g}$ of the pulverized sample was smeared on the stud housing the double adhesive carbon. The sample STUD was placed in the sample holder connected to the sample port and was introduced to the machine after which the chamber was closed. The sample was run for 5 seconds, and a prompt sound signified the sample was ready for imaging. The images were adjusted for sharpness, necessary zooming and refocusing and were then saved and printed.

\subsubsection{Fourier Transform Infrared Spectrometer (FTIR)}

The functional groups were identified using FTIR machine, the Agilent Carry FTIR Spectrometer (USA) with model number 630. Exactly $0.5 \mathrm{~g}$ of the sample each was measured and compressed into a pellet in a fixed small cup like holder which was put on the crystal optical path and clicked on the software to process. The sample alignment was checked for proper sampling and the coding of the samples. The measurement was clicked and the peaks acquired over a range of 400 - $4000 \mathrm{~cm}^{-1}$ using DTGS detector were selected for labeling by dragging to acquire the wave numbers as well as the transmittance. The generated and labeled peaks were saved and printed. 


\begin{tabular}{|c|c|c|}
\hline S/N & $\begin{array}{c}\text { Formulated Sample With Starch } \\
\text { Binder Code } \\
\text { (b) }\end{array}$ & $\begin{array}{c}\text { Formulated Sample With Gum Arabic } \\
\text { Binder Code } \\
\text { (c) }\end{array}$ \\
\hline 1. & AMAS & AMAGA \\
\hline 2. & BMAS & BMAGA \\
\hline 3. & CMAS & CPAGA \\
\hline 4. & APAS & APAGA \\
\hline 5. & BPAS & BMAGA \\
\hline 6. & CPAS & CMAGA \\
\hline
\end{tabular}

$\begin{array}{lll}\text { Key } & & \\ \text { A } & - & \text { Ratio }-65: 20: 12: 3 \text { (Tenny, 1998) } \\ \text { B } & - & \text { Ratio }-80: 16: 2: 2 \text { (Cohen, 1997) } \\ \text { C } & - & \text { Ratio - 85:10:4:1 (Proposed) } \\ \text { MA } & - & \text { Maize Stalk } \\ \text { S } & - & \text { Starch Binder } \\ \text { PA } & - & \text { Paw-Paw Stem } \\ \text { GA } & - & \text { Gum Arabic Binder }\end{array}$

\subsection{Rocket Design}

A PVC pipe was cut to the length of $300 \mathrm{~mm}$, with diameter of $48 \mathrm{~mm}$. in line with the rocket tube diameter system. The fin diameter for the rocket was obtained using aluminum sheet of $0.5 \mathrm{~mm}$ thickness which was cut to a required measurement of $50 \times 48 \mathrm{~mm}$.

A cone height of $50 \mathrm{~mm}$ by $40 \mathrm{~mm}$ was obtained by using Plaster of Paris (POP) which was molded using a mold to the required cone shape.

The propellant formulated using the charred plant biomass AMAS, AMAGA, BMAS, CMAGABPAS and CPAS and CCAS were used. The formulated composite propellants were measured to $300 \mathrm{~g}$ each and formed into the hallow tube geometry (shaped by compressing them). This was made into 6 different geometric according to the samples ID selected. The selection was done based on the Differential Scanning Colorimeter research with the ones having higher heat values. After the compression, it was then allowed to dry at room temperature. The ignition system was designed using a cable with the two ends soldered to the filament containing an ignition charge which was made thicker and it then connected to a match composition and to a power source (battery) which allowed flow of current that ignited the propellants.

\section{Result and Discussion}

\subsection{Physical Properties of Formulated and Charred Unformulated Samples}

The unformulated charred samples obtained were solid black powder with porous white patches on their surfaces, dark brownish while the formulated samples obtained were homogenous powdered form, black greyish with white patches.

\section{Chemical Characteristics}

\subsection{Differential Scanning Calorimeter (DSC)}

The results shows that formulated propellant samples of AMAS, BMAS and CMAS (Fig 1 ) to have $128-168-170^{\circ} \mathrm{C}$, 128-170 ${ }^{\circ} \mathrm{C}$, and $129-170{ }^{\circ} \mathrm{C}$ endothermic temperature values which indicates the phase change from the lower temperature to the highest endothermic temperature of $170{ }^{\circ} \mathrm{C}$ for the three different ratios of formulated propellants before combustion at the high peak temperature of exothermic value of $200.83,192.37$ and $197.54{ }^{\circ} \mathrm{C}$ for AMAS, BMAS and CMAS. DSC curve peaks for samples AMAGA, BMAGA and CMAGA in Fig 2 also displayed the first stage of the DSC curves of an endothermic values range of $170,120-170$ and $129-170{ }^{\circ} \mathrm{C}$ which indicates the transition state resulting to melting at the high endothermic temperature of $170{ }^{\circ} \mathrm{C}$ for the three samples respectively. The samples AMAGA, BMAGA and CMAGA displayed a DSC curve of an exothermic high peak value of 188.17, 193.35 and $209.52{ }^{\circ} \mathrm{C}$, which indicated that decomposition has occurred resulting to combustion. All the values obtained were close to the values reported by Goncalves et al, (2013) whose work was on ammonium per chlorate displaying similar DSC curves of first stage to be endothermic and the second stage to be exothermic with temperatures values of $246^{\circ} \mathrm{C}$ and $365^{\circ} \mathrm{C}$ respectively.

Propellants from APAS, BPAS and CPAS (Fig 3)displayed a DSC curve of endothermic of 82, 128.98 and 130- 164 ${ }^{\circ} \mathrm{C}$. This temperature change in the first stage of the endothermic indicated a transition change in the samples which results in the melting before decomposing and combusting as shown in the DSC curve with exothermic value of 227.80, 223.93 and $213{ }^{\circ} \mathrm{C}$ for APAS , BPAS and CPAS respectively. Samples of APAGA, BPAGA and CPAGA (Fig 4) indicated a DSC curve of endothermic values of 130,128 and $129-162{ }^{\circ} \mathrm{C}$ indicating the phase change gradually from the lower temperature and melting at the highest endothermic temperature before combustion at the high peak temperature of exothermic value of 208.16, 217.14 and $225.55{ }^{\circ} \mathrm{C}$ respectively for APAGA, BPAGA and CPAGA. All the values obtained were close to the values of Goncalves et al, (2013) displaying similar DSC curves of first stage to be endothermic and the second stage to be exothermic values of $246^{\circ} \mathrm{C}$ and $365^{\circ} \mathrm{C}$ respectively. 


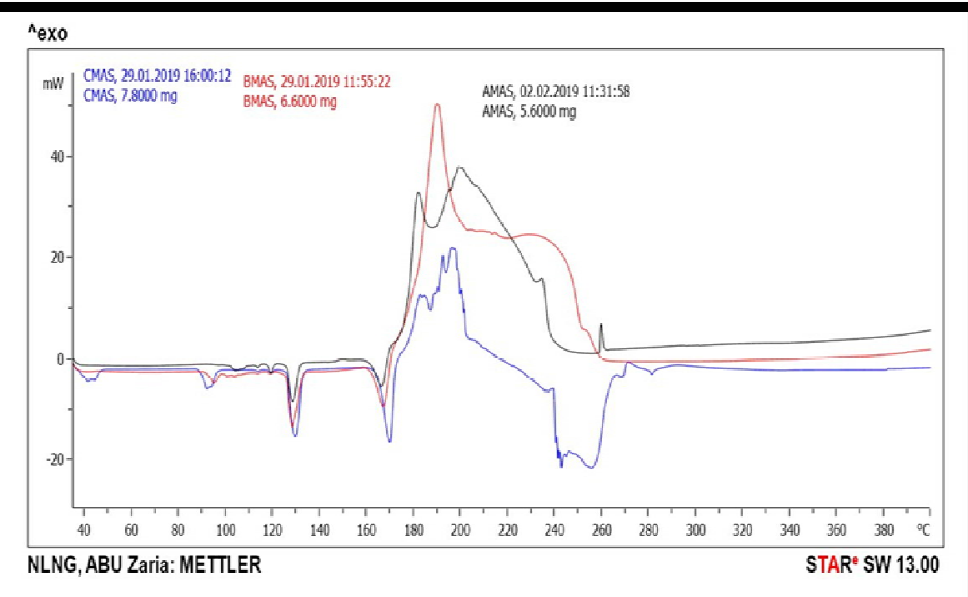

Figure 1: Showing the DSC Curve of AMAS, BMAS and CMAS KEY: Blue: CMAS, Red: BMAS,

Black: AMAS

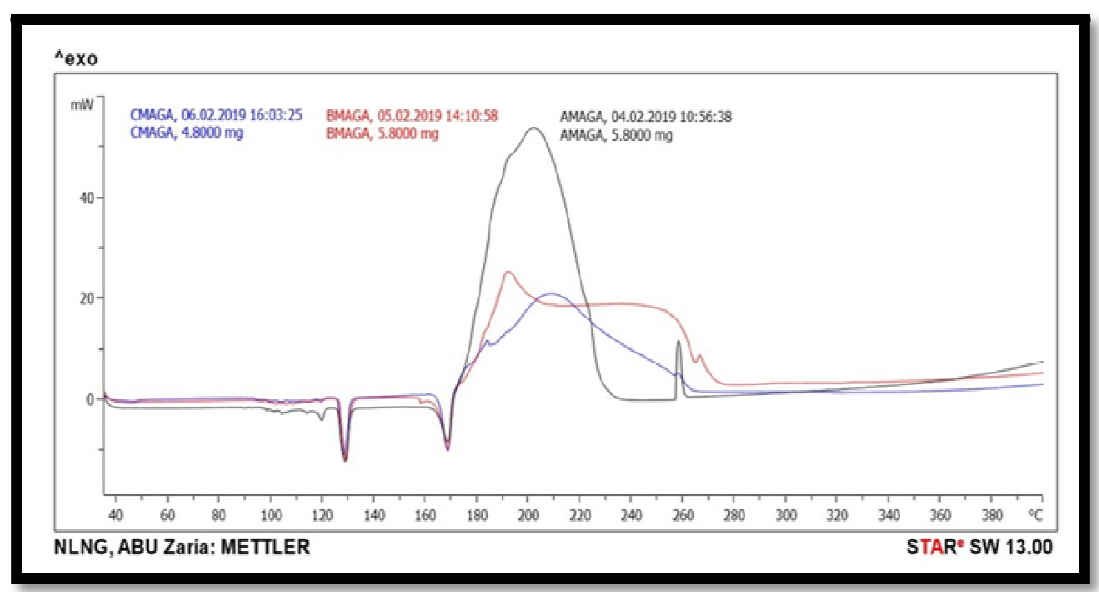

Figure 2: Showing the DSC Curve of AMAGA, BMAGA and CMAGA KEY: Blue: CMAGA, Red: $B M A G A$, Black: AMAGA

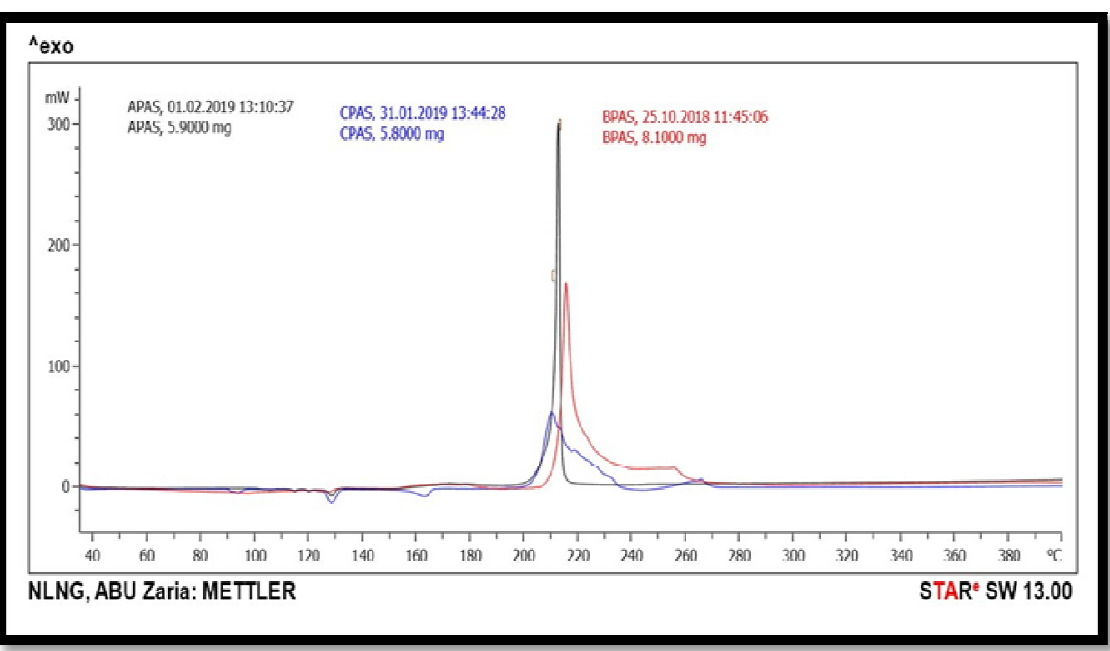

Figure 3: Showing the DSC Curve of APAS, BPAS and CPAS KEY: Black: APAS, Blue: CPAS,

Red: $B P A S$ 


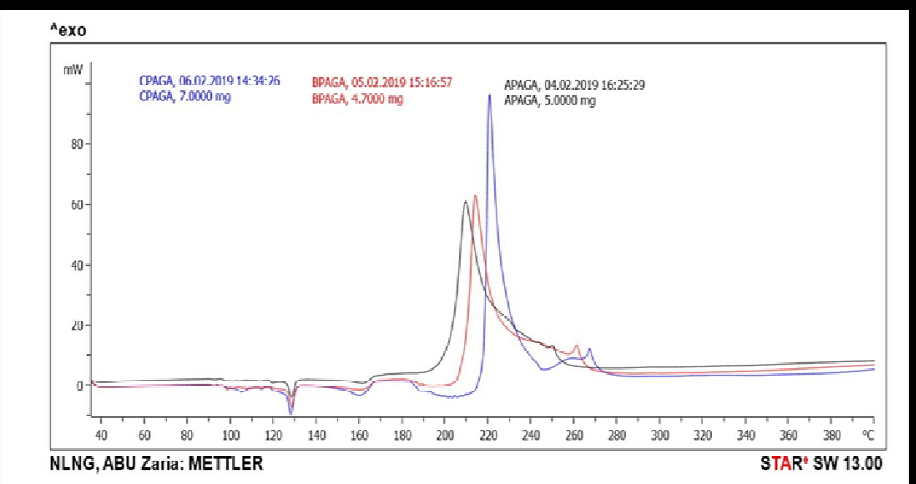

Figure 4: Showing the DSC Curve of APAGA, BPAGA and CPAGA KEY: Blue: CPAGA, Red: BPAGA,

Black: APAGA

\subsection{Scanning Electron Microscope (SEM)}

The SEM results of composite propellants formulated from maize stalk sample with codes (AMAS, BMAS, CMAS, AMAGA, BMAGA and CMAGA) revealed morphology of rhombic crater type, white uneven spherical, molten magma lump, flaky with trace like stripes and flaky uneven size particles as indicated in Fig 5 and Fig 6. The traces of white substance are shown to be embedded in the cluster indicating that the biomass had interacted with the sulphur and starch. The formulated sample dimension ranges from $65.4 \mu \mathrm{m}-3.77 \mu \mathrm{m}$. These images and dimensions observed were within the ranges of the study on analysis of low explosives in forensic investigation by Bonder (1998).

The formulated composite propellants from pawpaw stem with codes(APAS, BPAS, CPAS, APAGA, BPAGA and CPAGA) (Fig 8 and Fig 7) exhibited morphological characteristics of scraggy, honey comb shape, flake cake like, crater like with uneven holes and cracks and some white spheroidal substances and which appeared to be same for all the samples due to the same plant biomass.

The formulated sample dimensions ranges from $62.3 \mathrm{~mm}-5.3 \mathrm{~mm}$, which were observed to be similar to the range of values reported by Rodrigo et al (2005) in his study of characterization of a Hydroxy Terminated Rocket (HTPE) propellants.

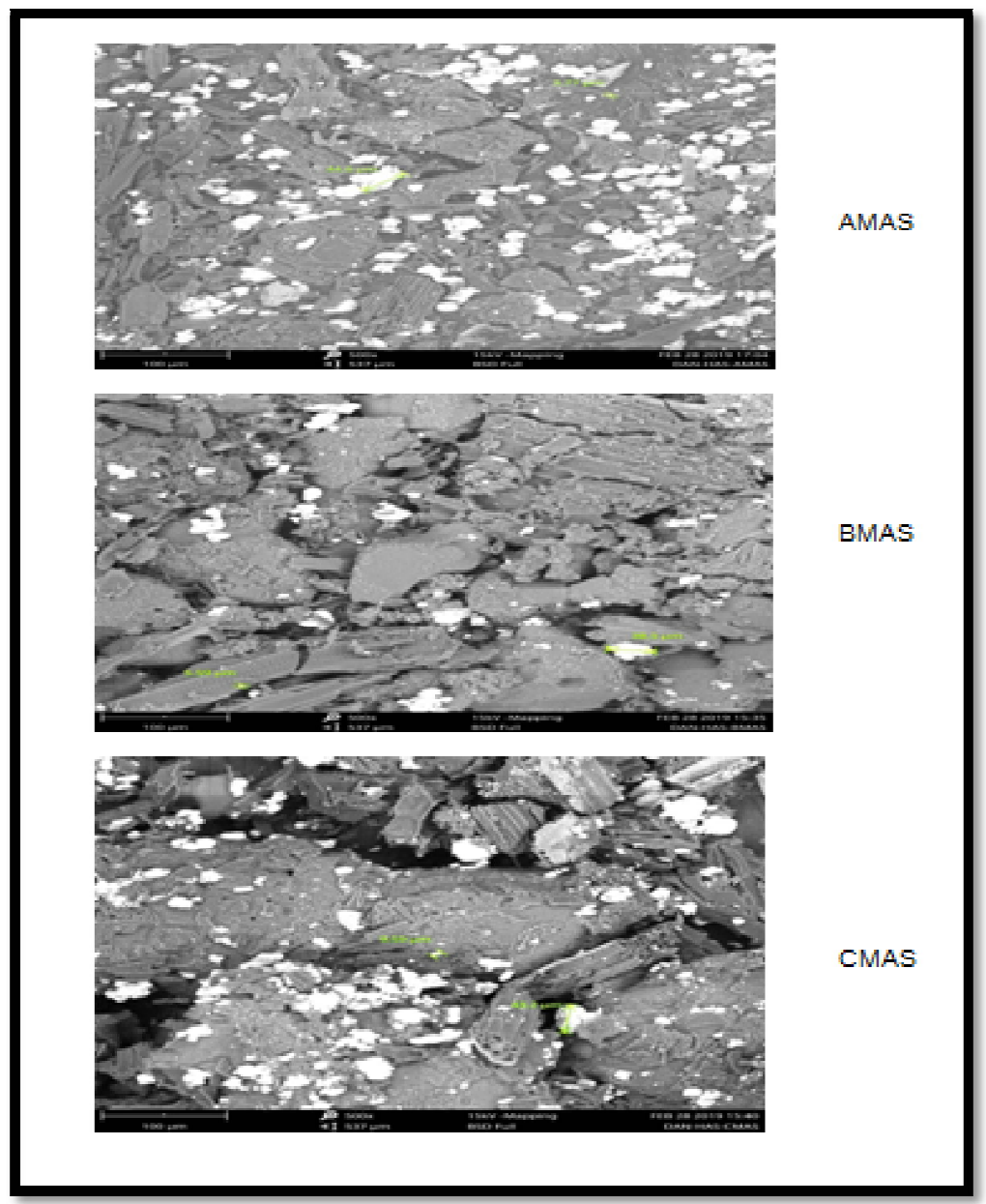

Figure 5: SEM Image, Morphology of Samples AMAS, BMAS, CMAS 


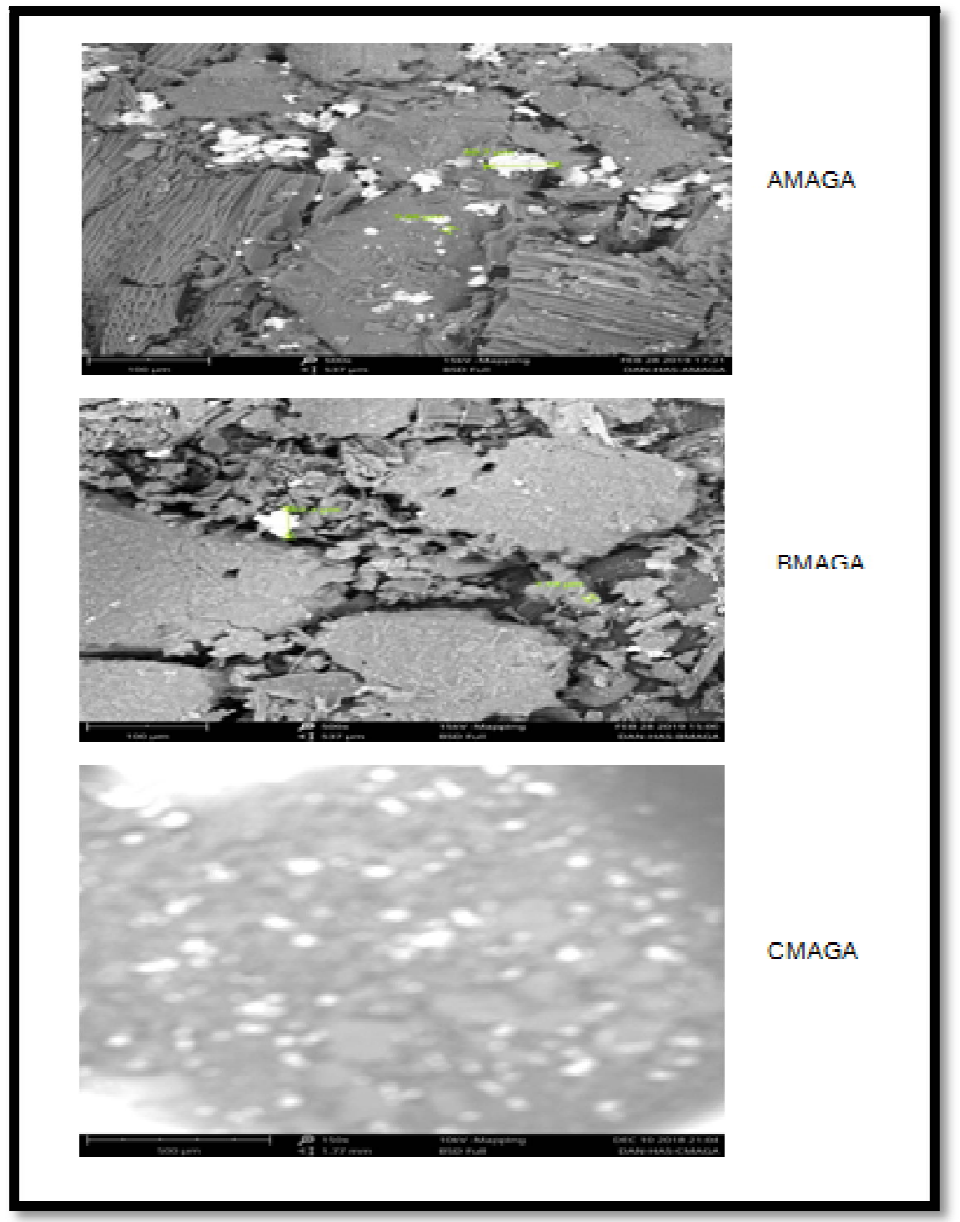

Figure 6: SEM Image, Morphology of Samples AMAGA, BMAGA and CMAGA

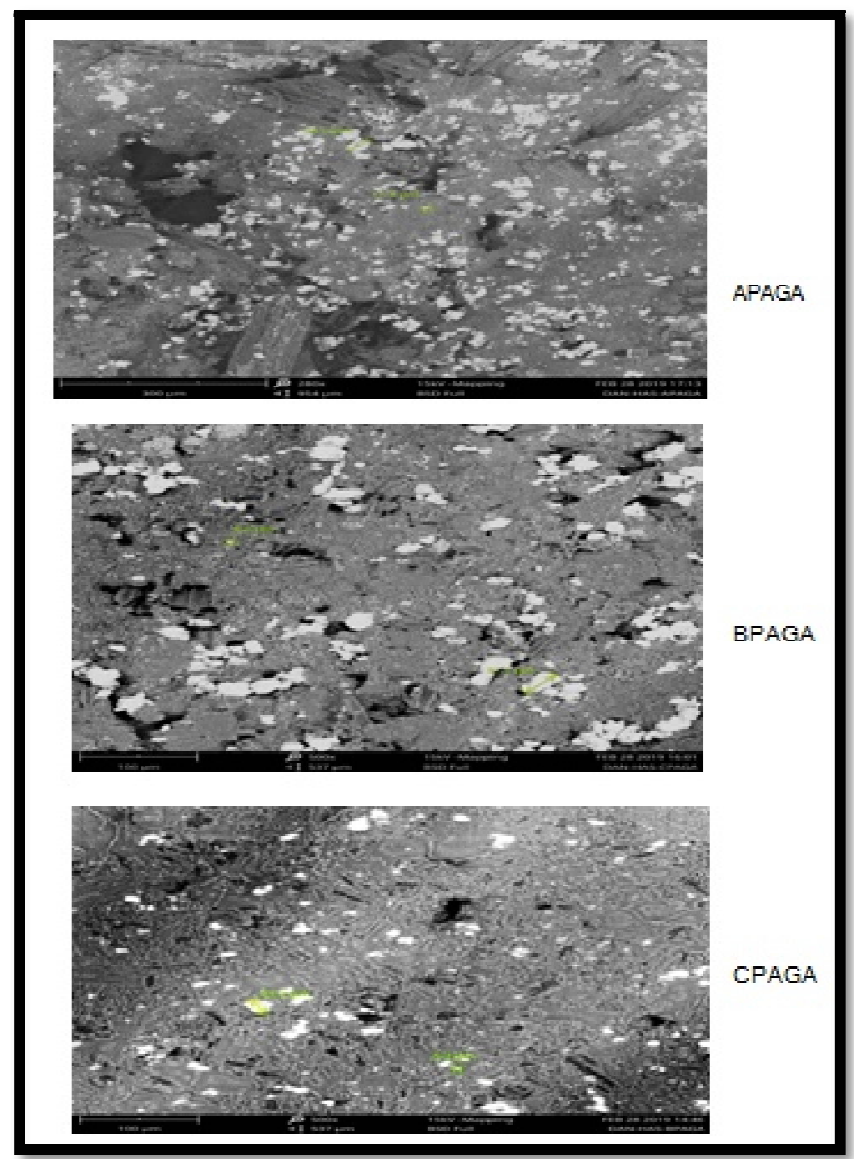

Figure 7: SEM Image, Morphology of Samples APAGA, BPAGA and CPAGA 


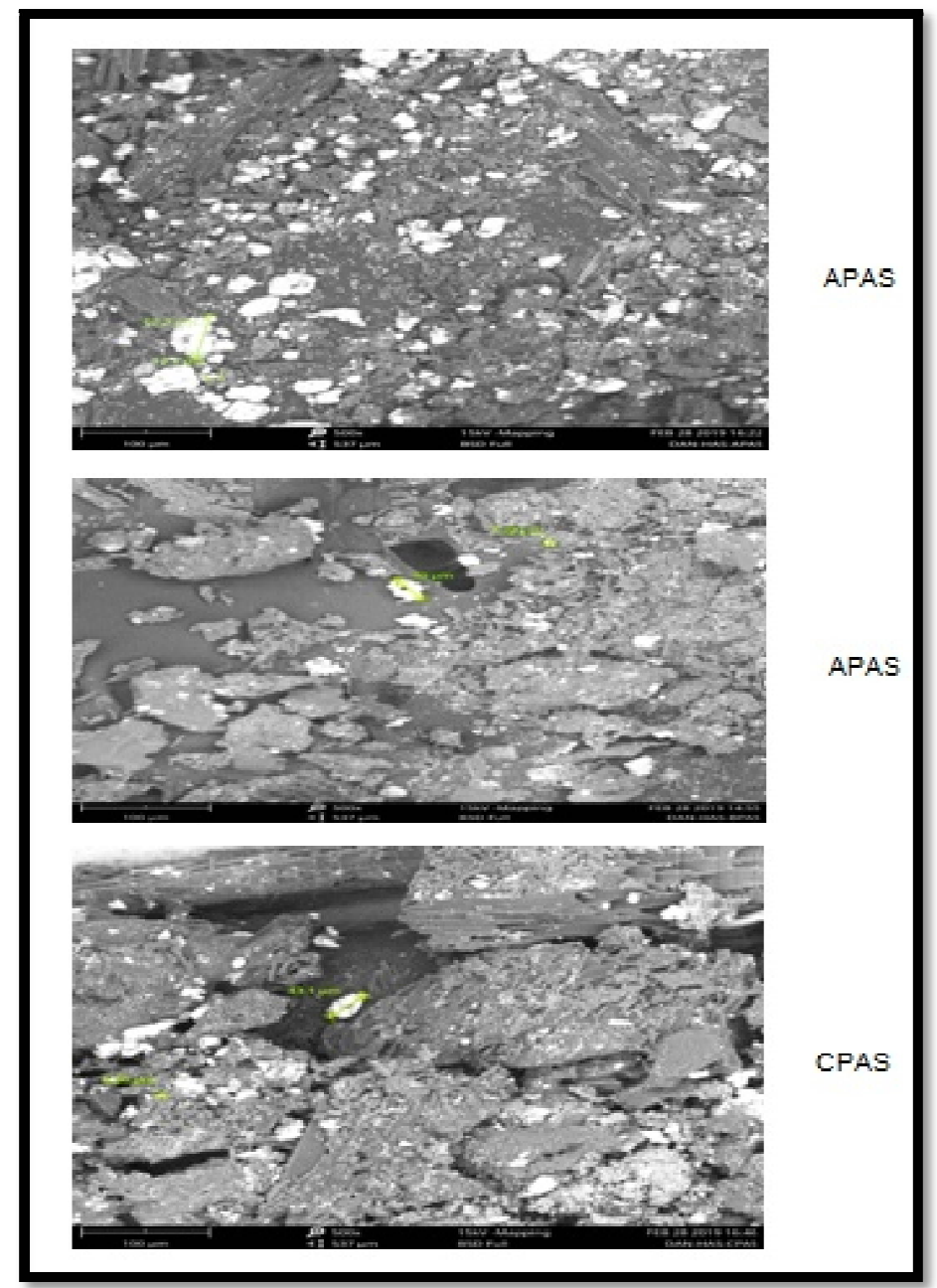

Figure 8: SEM Image, Morphology of Samples APAS, BPAS and CPAS

\subsection{Fourier Transform Infrared (FTIR)}

The results of the FTIR for maize stalk with codes AMAS, BMAS and CMAS (Fig 9) which represent different ratios A:B:C and AMAGA, BMAGA and CMAGA (Fig 10) did vibrational stretchings in the ranges of $3855.9 \mathrm{~cm}^{-1}-3609.9 \mathrm{~cm}^{-1}$, $3205.5 \mathrm{~cm}^{-1}-2115.8 \mathrm{~cm}^{-1}, 1578.5 \mathrm{~cm}^{-1}-1299.0 \mathrm{~cm}^{-1}, 2107.8 \mathrm{~cm}^{-1},-2115.3 \mathrm{~cm}^{-1}$. These values observed were as indicated in Fig 9. These spectra indicated the presence of alcohol, Esters, Nitro group, Amines, Isothiocyanate which showed the presence of AN, Carbon, Sulphurand binders used in homogenous mixture. This study agrees with the result of Anniyappanet al (2006) who detected Isothiocyanate at $1778.0 \mathrm{~cm}^{-1}$, alcohol at $3384.2 \mathrm{~cm}^{-1}$, Nitro group at $3354.2 \mathrm{~cm}^{-1}$, $\mathrm{C}=0$ at $1882.5 \mathrm{~cm}^{-1}$.

The pawpaw stem with codes APAS, BPAS and CPAS (Fig 11 representing different ratios of A;B;C and APAGA, BPAGA are CPAGA Fig 12) exhibited $\mathrm{O}-\mathrm{H}, \mathrm{N}-\mathrm{H}, \mathrm{C}=\mathrm{O}, \mathrm{N}=\mathrm{O}, \mathrm{N}=\mathrm{C}=\mathrm{S}$ and $\mathrm{C} \equiv \mathrm{C}$ vibrational stretchings in the range of $3738.5 \mathrm{~cm}^{-}$ 1 - $3216.7 \mathrm{~cm}^{-1}, 3213.0 \mathrm{~cm}^{-1},-2117.1 \mathrm{~cm}^{-1}, 1871.1 \mathrm{~cm}^{-1}, 1041.8 \mathrm{~cm}^{-1}, 1578.8 \mathrm{~cm}^{-1}-1300.8 \mathrm{~cm}^{-1}, 2120.9 \mathrm{~cm}^{-1}-1902.8 \mathrm{~cm}^{-1}$ and $1757.3 \mathrm{~cm}^{-1}-1753-7 \mathrm{~cm}^{-1}$. These spectra show the presence of Ester, Alcohol, Nitro group, Amines and Isothiocyanate. The Spectra values reported were within the range of spectra values observed by Cohen (1997) who detected Esters and Alcohol using tetrahydrobotane as binder. 


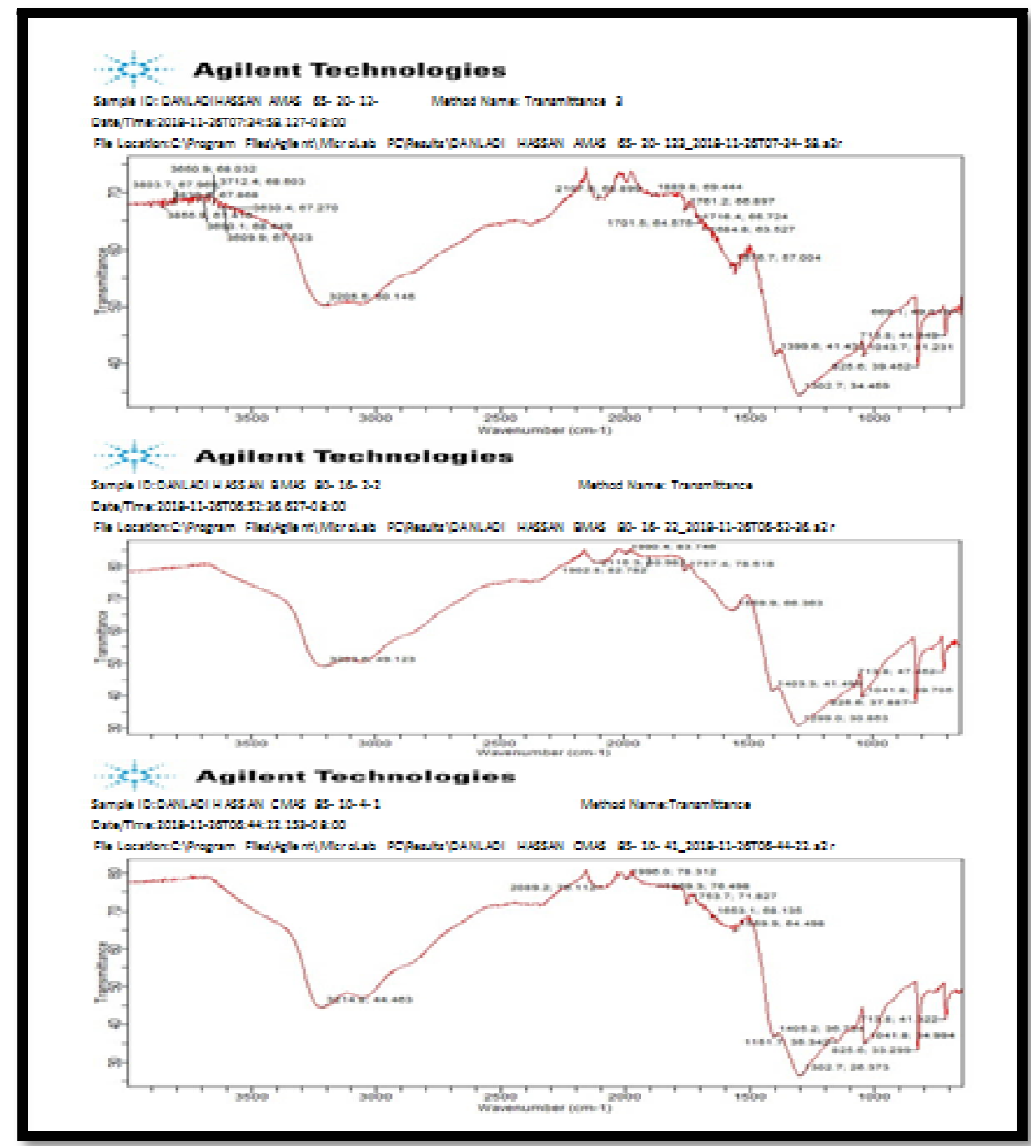

Figure 9: Spectral of Composite Samples of AMAS, BMAS and CMAS

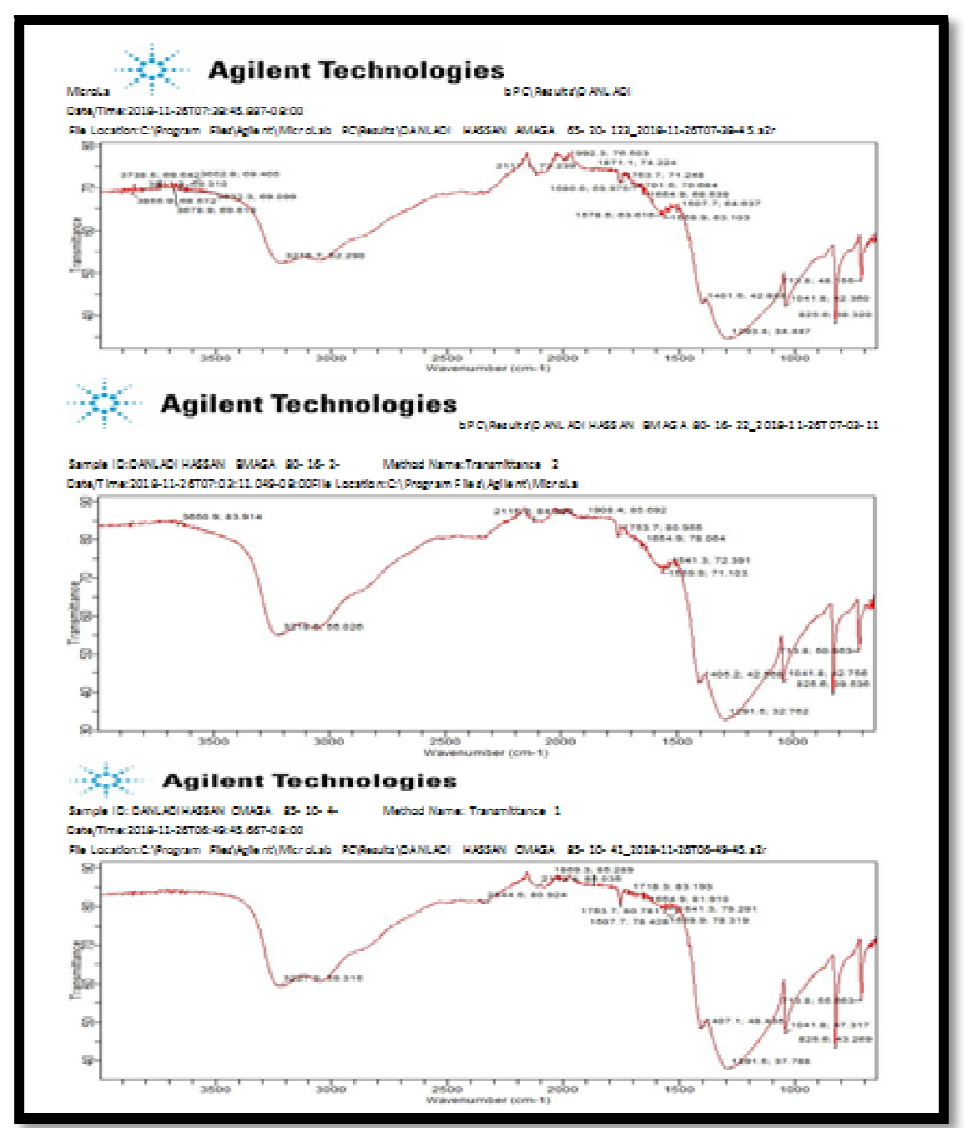

Figure 10: Spectral of Composite Samples of AMAGA, BMAGA and CMAGA 


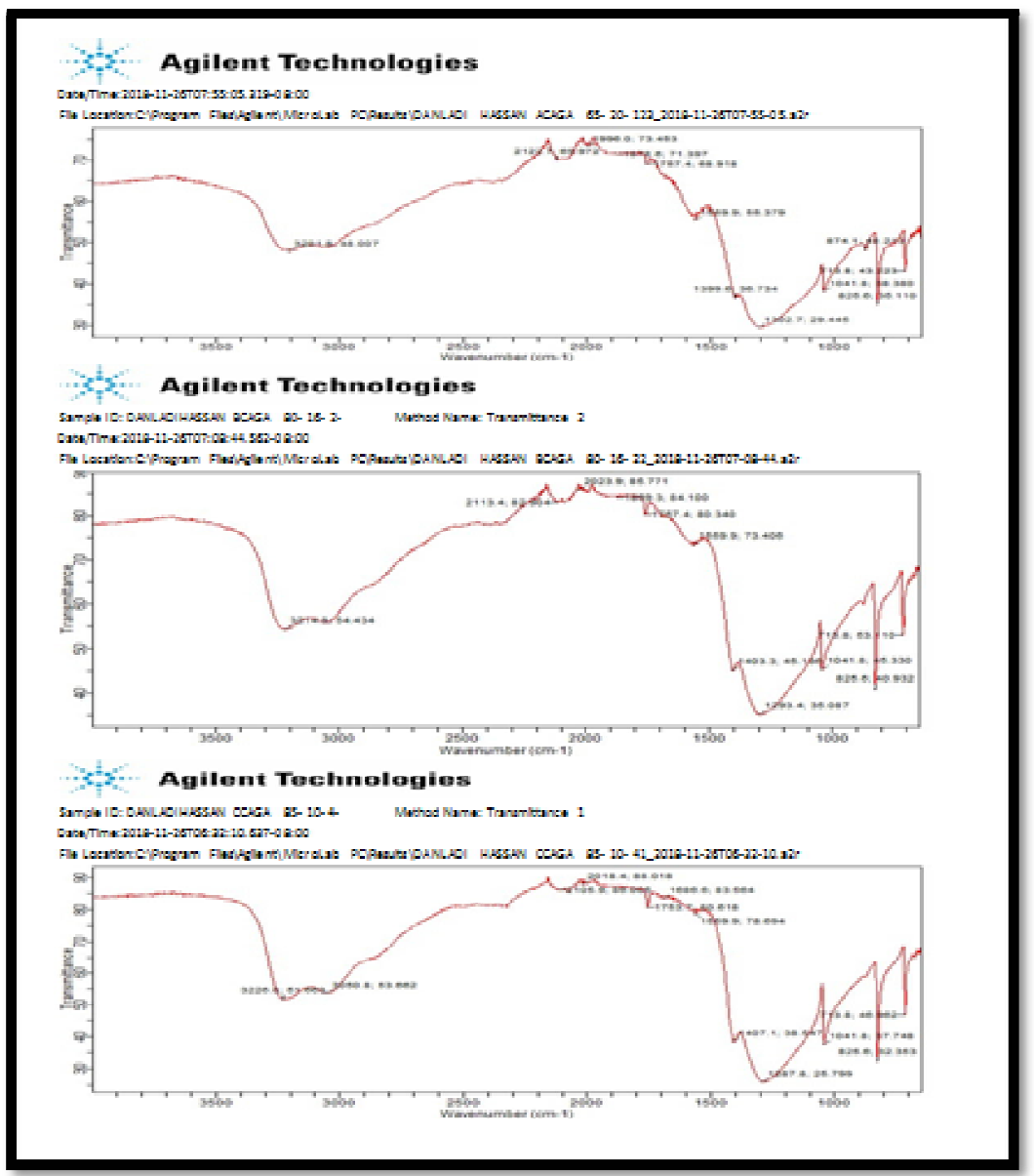

Figure 11: FTIR Spectral of Composite Sample of APAGA, BPAGA and CPAGA

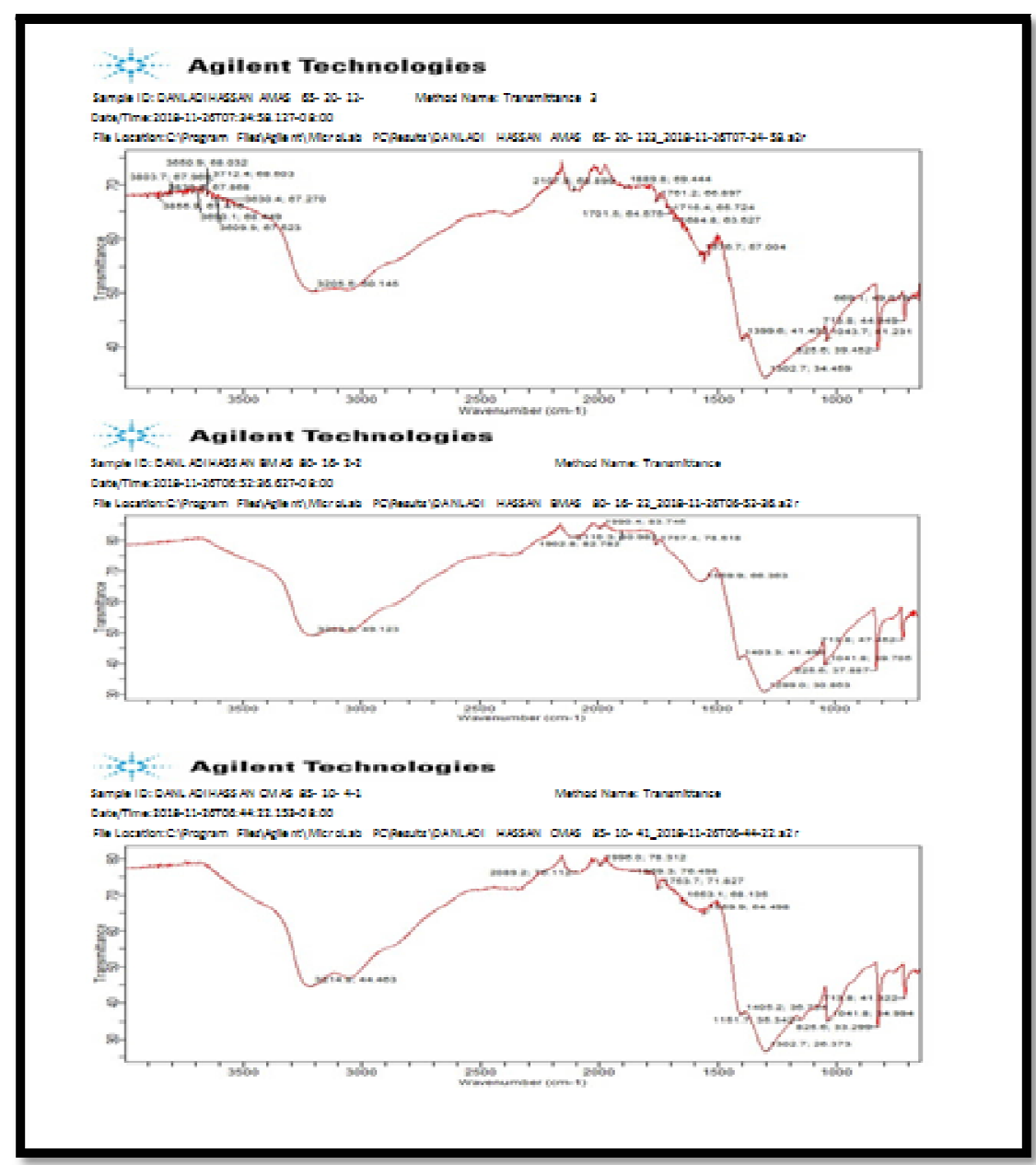

Figure 12: Spectral of Composite Sample of APAS BPAS and CPAS 


\subsubsection{Rocket Testing}

The designed rockets were tested at Research and Development Centre Field, Defence Industries Corporation of Nigeria (DICON) in order to evaluate the performances of the propellants. The revealed that propellants AMAS, CMAGA and CPAS did not lift off but burnt on the ground covering distances between $11 \mathrm{~m}-60 \mathrm{~m}$. However, propellants CPAS and BPAS projected distances of $280 \mathrm{~m}$ and $220 \mathrm{~m}$ respectively. High exothermic values and porosity of the surface area of the propellants giving good combustion accounted for this good performance.

\section{Conclusion}

The physical characterization of unformulated charred propellants revealed solid black powder with porous white patches, dark brownish and soft while the formulated were black grayish, homogenous powder. The FTIR result of the study revealed that all formulated propellants exhibited different vibrational stretchings such as $\mathrm{N}-\mathrm{H}, \mathrm{O}-\mathrm{H}, \mathrm{C}=\mathrm{O}, \mathrm{N}-\mathrm{O}$ and C$\mathrm{H}$ which indicated presence of Alcohols, Esters, Isothiocynate, Amines, Nitro groups, Alkenes among others. These vibrations were indicative of different functional groups thus confirming their presence in the composite propellants. SEM study of the formulated propellants shows morphology being predominantly crater, honey comb, scraggy, flaky, rhombic shape and fiber like stripe which were either large, small, dense spheroidal on the grain surface indicating composite formation. From the DSC results, the endothermic peaks range from $91-164{ }^{\circ} \mathrm{C}$ and exothermic range from $209-230{ }^{\circ} \mathrm{C}$ which indicates a transition change from lower temperature and melting at the highest temperature and thus indicating the burning ability of the propellants in space. The rocket testing revealed that propellants AMAS, CMAGA and CPAS did not lift off but burnt on the ground covering distances between $11 \mathrm{~m}-60 \mathrm{~m}$. However, propellants CPAS and BPAS projected distances of $280 \mathrm{~m}$ and $220 \mathrm{~m}$ respectively. The result therefore indicated that the propellants were effective in projecting the rockets.

\section{References}

i. Bonder, E.C. (1998). Analysis of Low Explosives in Forensic Investigations. Taylor and Francis Inc. London. 343385

ii. Cohen, N.S., (1997). 'Review of Composite Propellant Burn Rate Modeling', AIAA Journal, 3. (18): 277-293.

iii. Cohen, N.S., and Strand, L.D., (1981). 'An Improved Model for the Combustion of AP Composite Propellants', paper 81-1553, 17th Propulsion Conference.

iv. Daintith, J. (2000). Oxford Dictionary of Chemistry, $4^{\text {th }}$ Ed. Oxford University Press, New York, USA. PP 146-149.

v. Goncakves RFB, Rocco IAFF and Iha K. Thermal (2013) Thermal Decomposition Kinetics of Ages Solid Propellant Based on Ammonium Per Chlorate (AP/HIBP). 2013. Journal of INTECH Open Science.14:325-340

vi. Kevin, G., (1986). Ordnance Technology, Indian Journal of Naval Sea System Command. Vol.40, 1-23.

vii. Niklos, W., (2004). Improving the Mechanical Properties of Composite Rocket Propellant, a Paper Presented at Department of Fibre and Polymer Technology Royal Institute of Technology, Stockholm. 1-6, 283-287

viii. Rodrigo I.C., John M.B., and Esam K., (2005). Characterization and Thermal Decomposition Studies of a Hydroxy Terminated Rocket (HTPE) Copolymer and Binder for Composite

ix. Tenny, L.D., (1998). The Chemistry of Powder and Explosives. Angrif Press, Las Vegas, Navada, 195-214, 256-267 